\title{
Aspectos da biologia e fenologia de Oryza latifolia Desv. (Poaceae) no Pantanal sul-mato-grossense
}

\author{
Esther Campagna Bertazzoni ${ }^{1,3}$ e Geraldo Alves Damasceno-Júnior ${ }^{2}$
}

Recebido em 4/05/2010. Aceito em 17/05/2011

\begin{abstract}
RESUMO
(Aspectos da Biologia e Fenologia de Oryza latifolia Desv. (Poaceae) no Pantanal sul-mato-grossense). Oryza latifolia, uma espécie silvestre de arroz, aquática emergente, tolerante a inundação, tem vasta ocorrência nos campos inundáveis do Pantanal, principalmente na sub-região do Paraguai. O objetivo deste trabalho foi descrever aspectos da biologia e fenologia de O. latifolia em duas áreas ao longo do rio Paraguai. Cinco manchas de arroz foram analisadas em cada área. Um quadro ( $1 \mathrm{~m} \mathrm{x} 1 \mathrm{~m}$ ) era lançado com 20 repetições mensalmente em cada mancha, e foi estimada a porcentagem de cobertura, botão, floração, frutificação e panícula seca, medindo ainda a profundidade de água na mancha de dez/2006-nov/2007. A porcentagem de cobertura foi influenciada pelo nível da água na mancha, atingindo $80 \%$ durante a cheia nas duas áreas; o estabelecimento de plântulas ocorreu no período da seca, apenas nas bordas das manchas. A fase reprodutiva da espécie é curta e tem início durante a cheia. Esse período é correlacionado a um conjunto de variáveis ambientais como comprimento do dia e o nível da água. A dispersão da semente ocorre no início da vazante por barocoria, hidrocoria e zoocoria, e suas sementes permanecem viáveis, por cinco meses, até o período da seca.
\end{abstract}

Palavras-chave: arroz selvagem, plasticidade fenotípica, fenologia, Oryza latifolia, Pantanal

\begin{abstract}
(Aspects of the biology and phenology of Oryza latifolia Desv. (Poaceae) in the Pantanal wetland in Mato Grosso do Sul, Brazil). Oryza latifolia, a wild species of rice, aquatic emergent, tolerant of flooding, occurs on floodplains of the Pantanal wetland, mainly in the Paraguay River sub-region. The aim of this study was to describe aspects of the biology and phenology of O. latifolia in two areas (Serra do Amolar and Bracinho) along the Paraguay River, in the township of Corumbá (state of Mato Grosso do Sul). Five patches of wild rice were observed in each area. Twenty replicates of quadrats $(1 \mathrm{~m} \mathrm{x} 1 \mathrm{~m})$ were randomly established monthly in each patch, and percent cover was estimated; flowering, fruiting, production of dry inflorescence and water depth were monitored from December 2006 to November 2007. Percent cover is correlated with water level and day length in the plots, reaching up to $80 \%$ at flood time in both areas. Recruitment of seedlings occurs during the dry season only on the plot edges. The reproductive phase of the species is short and starts after the flood peak. This period is correlated with a set of environmental variables such as day length and water level. Dispersal occurs by barochory, hydrochory and ictiochory, at the onset of receding water, and seeds stay viable for five months up to the dry period.
\end{abstract}

Key words: floodplains, Oryza latifolia, Pantanal wetland, phenology, wild rice

\section{Introdução}

A família Poaceae é uma das principais famílias das angiospermas do ponto de vista econômico. A alimentação da maior parte da população mundial é baseada em plantas dessa família, como por exemplo: o trigo (Triticum aestivum), o milho (Zea mays), a aveia (Avena sativa), a canade-açúcar (Saccharum officinarum), o arroz (Oryza sativa) (Souza \& Lorenzi, 2005). O arroz cultivado (O. sativa) é considerado o alimento mais importante mundialmente, sendo parte da dieta de mais de um terço da população mundial (Khush, 1997).

O gênero Oryza possui duas espécies cultivadas (Oryza sativa e Oryza glaberrima) e 22 espécies silvestres distribuídas nos trópicos e subtrópicos. Dez espécies silvestres habitam a Ásia, cinco a África, duas a Austrália e quatro a América. As espécies americanas são Oryza glumaepatula, O. alta, O. grandiglumis e O. latifolia (Khush, 1997; IRRI, 2006). Essas espécies estão distribuídas do México até o norte da Argentina e são higrófitas (Oliveira, 1991).

\footnotetext{
1 Universidade Federal de Mato Grosso do Sul, Pós-Graduação em Biologia Vegetal, Campo Grande, MS, Brasil

2 Universidade Federal de Mato Grosso do Sul, Departamento de Biologia, Campo Grande, MS, Brasil

3 Autor para correspondência: esther_bertazzoni@yahoo.com.br
} 
No Pantanal brasileiro foi constatada a ocorrência de O. glumaepatula, O. gradiglumis e O. latifolia, mas não a de O. alta (Allem \& Valls, 1987). Popularmente, essas espécies são conhecidas como arroz-do-campo, arroz-do-brejo ou arroz selvagem.

A maioria dos trabalhos realizados com espécies silvestres de arroz envolvem aspectos genéticos com o propósito de selecionar genes que possam melhorar a espécie cultivada. Veasey et al. (2008) e Rosa et al. (2006) afirmam que trabalhos que visem a caracterização morfofenológica e agronômica das populações de espécies silvestres de arroz constituem uma lacuna a ser preenchida. Trabalhos com essa abordagem, além de caracterizar melhor essas espécies, são importantes em etapas iniciais de projetos de melhoramento, com o intuito de desenvolver populações com potencial agronômico em caracteres como produção, hábito de crescimento, altura da planta, resistência a pragas, entre outras.

O estudo fenológico destas espécies silvestres permite compreender suas respostas funcionais às variações ambientais, especialmente à sazonalidade hídrica. As gramíneas das savanas tropicais, de um modo geral, possuem estratégias de aquisição e conservação da água (Hesla et al., 1985), mas normalmente são intolerantes à seca estacional (Silva e Klink, 2001).

O. latifolia é uma gramínea aquática tolerante à inundação e tem vasta ocorrência nos campos inundáveis do Pantanal, principalmente na sub-região do Paraguai. Trabalhos realizados com essa espécie são escassos até o momento, consistindo principalmente de trabalhos florísticos que citem a ocorrência da espécie. Barbosa (2007) realizou análises químicas para as espécies nativas (O. latifolia e $O$. glumaepatula) colhidas nas regiões do Amolar e do Bracinho. Os testes mostraram que as sementes possuem $9,55 \%$ de proteínas, 2,17\% de lipídios, 10,46\% de umidade. A autora discute que os resultados apresentados demonstraram que o arroz nativo possui características nutricionais interessantes para maiores investigações, através de ensaios biológicos, por exemplo, principalmente quando relacionado ao teor protéico, já que possui concentração em proteínas maior até que algumas variedades de arroz cultivadas.

$\mathrm{Na}$ a comunidade ribeirinha do Pantanal, O. latifolia possui alto valor e poder forrageiro para os animais, inclusive o gado (Pott \& Pott, 2000; Allem \& Valls, 1987), daí sua importância econômica.

O arroz-do-campo foi muito utilizado por comunidades indígenas da região. Os Guatós, segundo reportado por Oliveira (2002), no passado colhiam o arroz em banhados e bacias da região e o estocavam para consumo. A colheita dos grãos era realizada em canoinhas de madeira, sacudindo as espigas, que com facilidade caíam na canoa quando o fruto já estava maduro (Matos 1875).

A utilização do arroz-do-campo pela comunidade ribeirinha não-indígena, em especial na região do Amolar, era desconhecida até o momento. Trabalhos envolvendo a utilização de espécies nativas, incluindo O. latifolia e $O$. glumaepatula, na dieta alimentar e a sua valoração fazem parte de projetos realizados com a comunidade local. Bortolotto (1998) reporta que os conhecimentos tradicionais associados são importantes para manter os recursos em casos de aproveitamento. $\mathrm{O}$ conhecimento sobre a biologia e a fenologia da espécie, cuja obtenção é proposta por este trabalho, pode auxiliar no estímulo à comunidade local para a colheita destinada à subsistência e como incremento à renda familiar, comercializando o produto, visto que a região é um importante referencial turístico.

O conhecimento científico de espécies nativas como o arroz-do-campo, possuidoras de valor agregado, seja ele nutricional ou econômico, tem, entre outros papéis, o de subsidiar não somente o entendimento da biologia da espécie, mas também integrar as comunidades na preocupação com seu desenvolvimento e com a biodiversidade, buscando equilíbrio entre natureza e utilização de suas riquezas.

Nesse contexto, o presente trabalho tem por objetivo descrever alguns aspectos da biologia e fenologia de $O$. latifolia, uma espécie silvestre de arroz em duas áreas ao longo do rio Paraguai, Corumbá (MS), Brasil.

\section{Material e métodos}

\section{Área de estudo}

O Pantanal brasileiro é a maior planície de inundação contínua do planeta, ocupando grande parte da Bacia do Alto Paraguai, grande parte da qual fica em território brasileiro. Expressa uma mistura de áreas alagadas, áreas de inundação e áreas de terra firme que contribuem para a diversidade vegetacional. A altitude varia de 80 a $150 \mathrm{~m}$ e o solo é predominantemente hidromórfico (Prance $\&$ Schaller, 1982; Radambrasil, 1982). Sua formação geológica é recente e ocorreu por depósitos de sedimentos do Quaternário. Do ponto de vista fitogeográfico, apresenta um mosaico integrado de paisagens com influência predominante de Cerrados e Mata Atlântica, a leste; da Amazônia, ao norte, e do Chaco, a oeste (Prance \& Schaller, 1982; Allem \& Valls, 1987).

Segundo a classificação de Köppen, o clima da região é do tipo Aw - quente e úmido com estação chuvosa (outubro a abril) no verão e estiagem no inverno (maio a setembro), com precipitação média anual de $1,070 \mathrm{~mm}$ (Soriano, 1997). A temperatura média anual é de $24^{\circ} \mathrm{C}$, apresentando-se mais amena nos planaltos e mais quente nas planícies (ANA et al., 2004).

O Pantanal brasileiro está dividido em onze sub-regiões (Silva e Abdon, 1998) ou em onze pantanais, como é referenciado pela comunidade local. Uma dessas sub-regiões é o Pantanal do rio Paraguai, local deste estudo. Está localizado na borda oeste, constituído por um conjunto de serras e planícies que figuram em uma mistura de campos e cerrado com floresta semidecídua e vegetação ciliar ao longo do rio Paraguai (Prance \& Schaller, 1982). 
O rio Paraguai possui uma extensão de $2.621 \mathrm{~km} \mathrm{e}$ tem como principais afluentes os rios Jauru, Cabaçal, Sepotuba, Cuiabá, São Lourenço, Taquari, Miranda e Aquidauana. O contato do rio Paraguai com a extensa planície de inundação causa mudanças expressivas nas características da água durante as fases do ciclo hidrológico. Devido à baixa declividade $(2,5 \mathrm{~cm} / \mathrm{Km})$ desta planície no sentido norte-sul, a água que cai nas cabeceiras do rio Paraguai chega a gastar quatro meses ou mais para atravessar todo o Pantanal. Esta situação promove um fenômeno interessante que é a cheia em Corumbá durante um período seco. A estabilização da cheia ocorre geralmente nos meses de março a abril, sendo a vazão desse rio também lenta (Hamilton et al., 1996).

A cheia do rio Paraguai inunda uma área que pode atingir até $16.000 \mathrm{~km}^{2}$ (Hamilton et al., 1996), que é dominada por vegetação herbácea denominada de campos inundáveis (Pott \& Pott, 2000). Esses campos inundáveis, em sua maioria, apresentam dominância de espécies do gênero Oryza, e são comumente chamados de arrozal ou campos de arroz, formando uma extensa mancha na vegetação, tendo em alguns lugares até 5.000 hectares.

A espécie Oryza latifolia (latis - largo e folium - folha, alusão à grande largura da folha em relação a outras espécies do gênero) é uma gramínea aquática nativa pouco conhecida popularmente, assim como as demais espécies selvagens (Allem \& Valls, 1987; Pott \& Pott, 2000). Reitz (1982) considera a espécie como cespitosa ereta e Pott \& Pott (2000) a classificaram como erva aquática emergente, baseados em Irgang et al. (1984). Essa espécie é perene, estival, sem rizomas, chegando até a 6,5 $\mathrm{m}$ de comprimento (em época de cheia), com panícula típica laxa, presença de lígula membranosa, aurículas pilosas vistosas, lema com arista apical, fruto do tipo cariopse. Seu crescimento varia de acordo com a sazonalidade do Pantanal.

Este estudo foi realizado em duas áreas no município de Corumbá (Figura 1), sendo em cada área amostradas cinco manchas de Oryza latifolia, totalizando dez manchas:

\section{Área 01}

Campos de inundação do corixo Bracinho, um corixo próximo ao perímetro urbano de Corumbá (coordenadas: S 18 $58^{\prime} 32,0^{\prime \prime} \mathrm{W} 57^{\circ} 35^{\prime} 4,5^{\prime \prime}$; S $18^{\circ} 57^{\prime} 3,5^{\prime \prime} \mathrm{W} 57^{\circ} 36^{\prime} 32,6^{\prime \prime}$; S $18^{\circ} 58^{\prime} 5,0^{\prime \prime}$ W $57^{\circ} 36^{\prime} 21,5^{\prime \prime}$; S $18^{\circ} 58^{\prime} 38^{\prime \prime}$ W $57^{\circ} 37^{\prime} 51,6^{\prime \prime}$; S $\left.18^{\circ} 58^{\prime} 44,5^{\prime \prime} \mathrm{W} 57^{\circ} 35^{\prime} 27,4^{\prime \prime}\right)$.

\section{Área 02}

Campos inundáveis próximos ao Porto do Amolar, na Serra do Amolar (coordenadas: S 170 59’ 22.6” W 57 $27^{\circ}$ ' $12.4^{\prime \prime}$; S $18^{\circ} 00^{\prime}$ 06.2" W $57^{\circ} 27^{\prime} 58.5^{\prime \prime}$; S $18^{\circ} 06^{\prime} 26.5^{\prime \prime}$ W $57^{\circ} 26^{\prime} 05.4^{\prime \prime}$; S $18^{\circ} 04^{\prime} 01.6^{\prime \prime}$ W $57^{\circ} 26^{\prime} 28.6^{\prime \prime}$ e S $17^{\circ} 58^{\prime}$ $55.5^{\prime \prime}$ W $\left.57^{\circ} 29^{\prime} 31.2^{\prime \prime}\right)$.

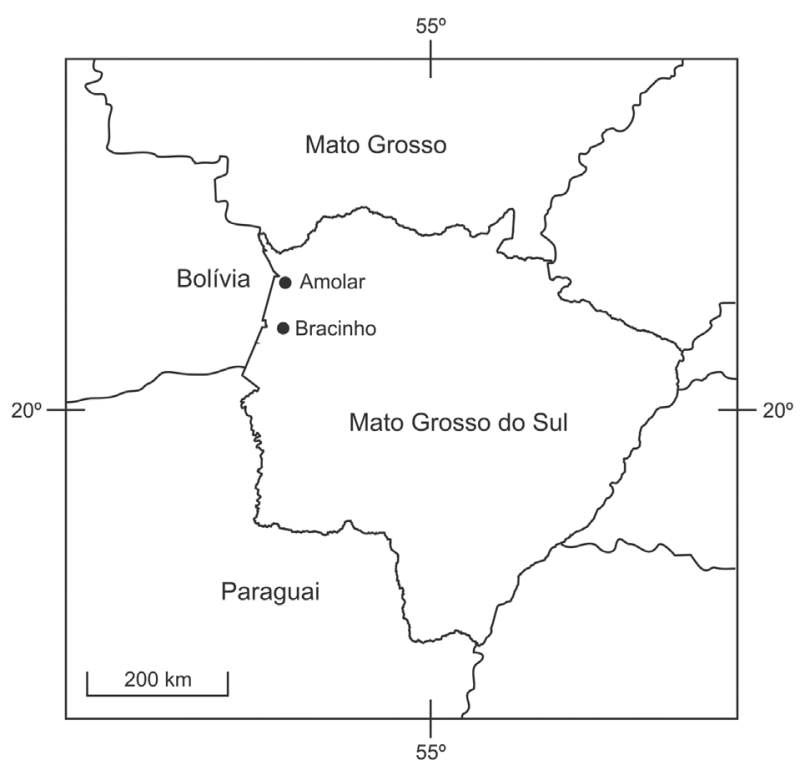

Figura 1. Localização da área de estudo (Bracinho - área 1 e Amolar - área 2) no município de Corumbá, Mato Grosso do Sul, Brasil.

\section{Biologia e Fenologia Vegetativa}

A escolha das manchas de O. latifolia obedeceu a um critério pré-estabelecido. Sua ocorrência tinha que ser próxima ao rio Paraguai, em campos inundados por esse rio; as manchas teriam que ser isoladas, por corixo, rio, morro ou mesmo por alguma vegetação diferenciada que as delimitasse (mata ciliar, p.e). As coletas foram realizadas mensalmente entre a terceira e quarta semana no período de dezembro/2006 a novembro/2007. O acesso às manchas era feito com barcos pequenos a motor. Em época de seca, o barco era atracado na borda do campo e as coletas realizadas a pé. Conforme esses campos inundavam, o acesso dentro da mancha era feito com barco e com zinga (bastão de taquara com $\pm 4,00 \mathrm{~m}$ e um tripé em uma das pontas), deslizando sobre a vegetação.

A dificuldade na marcação de indivíduos para acompanhamento permanente em função do regime de inundação levou à avaliação da variação da porcentagem de cobertura nas manchas ao longo do ano. Essa porcentagem era estimada mensalmente, usando um quadrado de madeira $(1 \mathrm{~m}$ $\mathrm{x} 1 \mathrm{~m}$ ). Esse quadro era jogado ao acaso na mancha, e esse processo era repetido 20 vezes. Em cada quadro era estimada a porcentagem de cobertura de O. latifolia e medida a profundidade de água na mancha. Além desses dados foram observadas a altura máxima e mínima dos indivíduos acima da lâmina d'água.

Num segundo momento, após o pico da cheia, em cada mancha foram marcados 40 indivíduos da espécie para o acompanhamento do crescimento e quantificação de rebrota. Em cada indivíduo foi contado o número de novos ramos que emergiram dos colmos. O material testemunho da espécie está depositado no CGMS, sob o número de registro 19799. 


\section{Fenologia Reprodutiva}

Mensalmente eram estimadas as porcentagens de colmos com botão, com floração, frutificação, inflorescência seca e perfilhos em relação ao total da mancha. A marcação de indivíduos e também de parcelas permanentes para o acompanhamento e quantificação, principalmente da fase reprodutiva, não teve êxito. Nas tentativas de marcação, os indivíduos ficavam submersos com a inundação, não sendo encontrados nos meses subseqüentes e as parcelas, mesmo fixadas ao solo, também ficavam imersas ou cobertas conforme o crescimento da vegetação da mancha.

No período reprodutivo da espécie foram avaliados por estimativa de porcentagem os eventos: botão, sinflorescência, fruto jovem (coloração da espigueta amareloesverdeada), fruto em maturação (coloração da espigueta acastanhada), fruto maduro (coloração da espigueta preta).

Dados meteorológicos para o município de Corumbá foram fornecidos pela estação climática do CPTEC/ INPE e dados hidrológicos pela Base Naval Fluvial de Ladário (BNFL), que fica próximo a Corumbá. Para a região do Amolar alguns dados foram fornecidos pela CPRM/ANA.

As análises estatísticas foram realizadas no Minitab 12. Ajustes de regressão simples foram usados para avaliar as relações existentes entre os parâmetros fenológicos (cobertura, botão, sinflorescência, fruto em maturação, fruto maduro, sinflorescência seca) e as variáveis ambientais para cada área, que permitiram inferir as determinantes que condicionam cada fase no ciclo da espécie estudada.

\section{Resultados e discussão}

\section{Biologia e fenologia vegetativa}

No Pantanal, o arroz-do-campo (O. latifolia) ocorre em campos inundáveis, e por estar em um ambiente sazonal, seu crescimento varia de acordo com o regime das cheias, conforme aumenta o nível de água nas manchas. A variação do crescimento em função da quantidade de água também é observada para a espécie cultivada (O. sativa), e, segundo Métraux \& Kende (1984) há um aumento na taxa de divisão celular, que ocorre à medida que se eleva a altura da lâmina d'água no arroz cultivado.

A parte do indivíduo que emerge em O. latifolia, no período da cheia, variou de 20 a $150 \mathrm{~cm}$ de altura e, somando-a ao nível da água, alguns indivíduos chegaram a $6,0 \mathrm{~m}$ de altura. Matos (1875) cita em seus relatos que o arroz-docampo chegava a atingir de dois a três pés $(0,8 \mathrm{~m}$ a $1,20 \mathrm{~m})$ fora d'água e de cinco a seis pés ( $2 \mathrm{~m}$ a 2,4 $\mathrm{m}$ ) submerso no período de cheia. Rubim (1994) reporta para O. glumaepatula e O. grandiglumis, na região amazônica, uma média de 3,0 $\mathrm{m}$ fora da lâmina da água e uma profundidade de 2,7 a $2,8 \mathrm{~m}$.
No pico das cheias, as primeiras sinflorescências surgem, aumentando ainda mais a área de cobertura da espécie em relação à mancha (Figura 2A). Ao final das cheias, os indivíduos vão deitando conforme a água vai baixando, $\mathrm{e}$ de cada nó do colmo emerge outro ramo, que mais tarde se fixará ao solo quando as águas baixarem. E o mesmo ocorre todo ano a cada vazante, formando uma rede, em que vários indivíduos vão emergindo à medida que o nó fica exposto na lâmina d'água (Figura 2B).

Pouco antes do início do trabalho, em novembro de 2007 , as manchas de arroz nas duas áreas não estavam secas, pois no ano de 2006 não houve seca total das manchas. A altura da lâmina d'água era de $0,24 \mathrm{~m}$ em média no Amolar e 0,37 m em média no Bracinho. Nesse período, as manchas já estavam sendo inundadas e os colmos de arroz que floresceram e frutificaram no ano de 2006 estavam prostrados. O número de novos ramos emergentes de cada colmo nas duas áreas, em média, foi 12. A colonização da espécie por sementes foi observada em outubro de 2007, no período da seca, apenas nas bordas das manchas, tanto no Amolar quanto no Bracinho (Figura 3a). Quando as águas baixaram por completo, as primeiras plântulas de O. latifolia emergiram. O vestígio da semente pôde ser observado na plântula, com a presença dos lemas presas à raiz, o que não ocorre nos ramos no interior da mancha (Figura 3 ).

A porcentagem de cobertura variou positivamente ao longo do ano em relação ao nível de água na mancha. Essa relação se mostrou significativa tanto para as manchas do corixo Bracinho $\left(\mathrm{r}^{2}-73,8,1 \% ; \mathrm{p}<0,001\right)$ (Figura 4), quanto para as manchas do Amolar $\left(r^{2}-26 \% ; p<0,001\right)$ (Figura 5). À medida que as manchas estavam sendo inundadas, a dominância da espécie aumentava. No pico das cheias, nas manchas do Amolar a média de porcentagem de cobertura foi de $81 \%$ e, nas manchas do Bracinho, no mesmo período, foi de $67 \%$. Conforme ocorria o escoamento da água, a porcentagem de cobertura também decaía, chegando a atingir médias de $44 \%$ no Amolar e $22 \%$ no Bracinho. Foi observado que, após a seca completa da mancha e com o início das chuvas, a espécie teve um aumento continuo novamente (Figuras 6 e 7). Sendo assim,observou-se que a água é um fator determinante na área de cobertura dessa espécie, bem como que o ciclo de vida de arroz-do-campo é fortemente influenciado pelo regime hídrico dos rios. O mesmo foi constatado por Rubim (1994) para O. glumaepatula e O. grandiglumis.

Após a dispersão das sementes, que ocorre no início da vazante, foi verificado através de marcações em 40 ramos em cada mancha, que a espécie cessa seu crescimento longitudinal (Figuras 19 e 20), apenas com novos ramos emergindo (Figura 21). Essa estratégia confere à O. latifolia um recrutamento contínuo e a conseqüente dominância nas manchas amostradas. A inserção de novos recrutas na época seca e o rebrotamento garantem a perpetuação da espécie. 

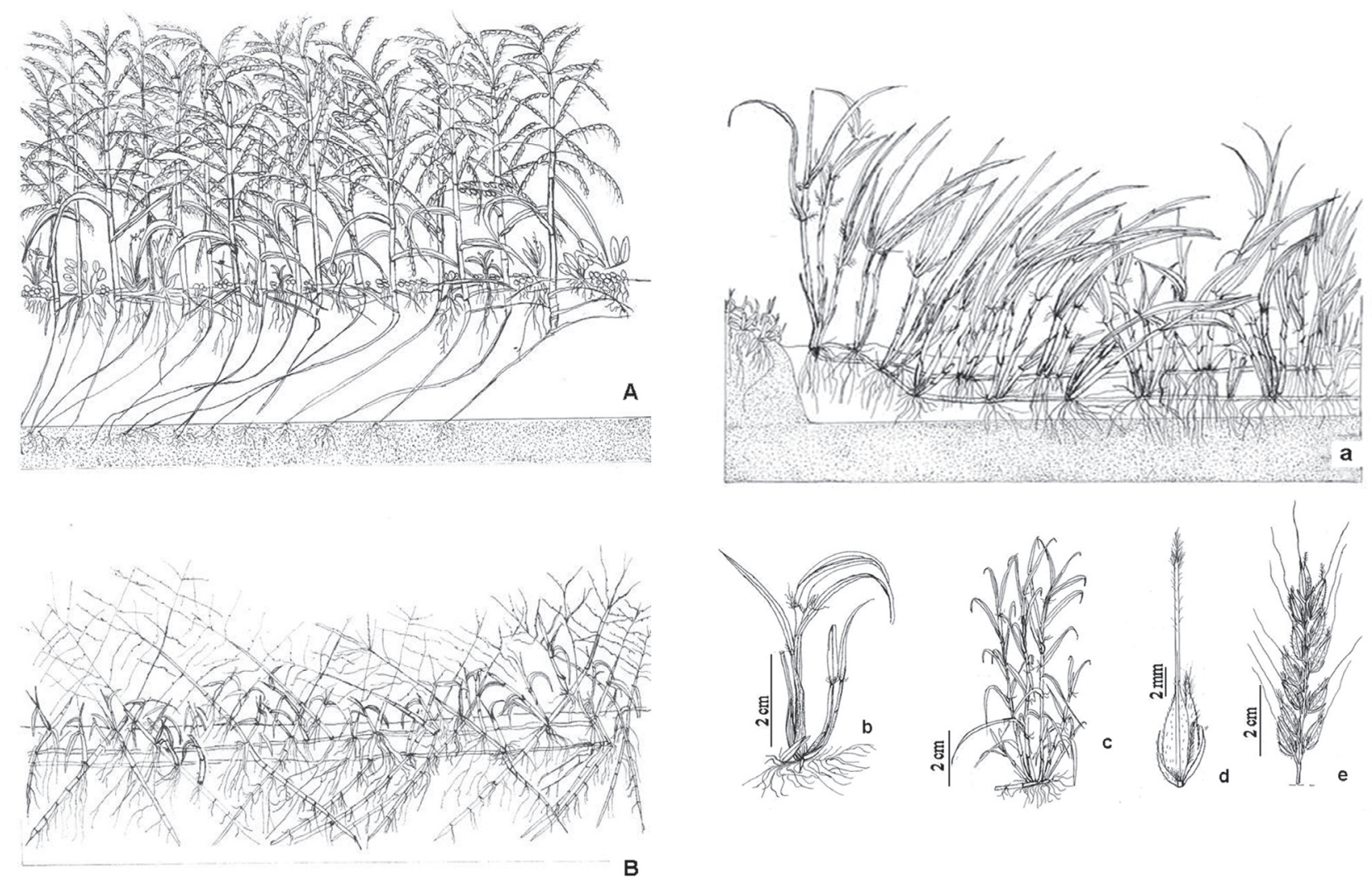

Figuras 2a-b. 2a. Esquema da mancha de arroz-do-campo (Oryza latifolia) no pico da cheia. Quando chega o pico da cheia, as primeiras sinflorescências se abrem, aumentando a área de cobertura da espécie. $2 b$. Esquema da mancha de arroz-do-campo (O. latifolia) no período de vazante. Quando a água começa a baixar, dos nós de cada colmo que fica exposto na lâmina d'água rebrotam novos ramos.

\section{Fenologia Reprodutiva}

A espécie O. latifolia é caracterizada por um período reprodutivo curto, enquanto que os perfilhos ocorreram durante todo o ano, com redução no pico reprodutivo. Esse padrão foi observado para todas as manchas nos dois locais de estudo. A produção de flores e frutos foi concentrada em uma pequena faixa de tempo, entre os meses de maio e junho, coincidindo com o início da vazante. O mesmo não foi observado no ano anterior, quando a floração e a frutificação ocorreram nos meses de junho e julho, e o início da vazante ao final de junho. De 2006 para 2007 não houve seca completa nas manchas, por que as águas não baixaram completamente e a cheia chegou mais cedo. A cheia do rio Paraguai durante o período desse estudo, para a região do Amolar, se estabilizou em 13 de abril (CPRM/ANA), enquanto na régua de Ladário a estabilização foi em 19 de maio (BNFL). Com isso, pode-se constatar que não é o pico da cheia que induz a floração, mas que a planta floresce durante a cheia.

No período de cheia, nos indivíduos de O. latifolia, surgiram as primeiras sinflorescências. O botão, a abertura

Figuras 3a-e. 3a. Esquema da mancha de arroz-do-campo (O. latifolia) na época da seca. Quando as manchas de arroz secam, novos indivíduos germinam na borda das manchas e também novos ramos rebrotam dos colmos caídos no restante da mancha. 3b. Plântula de O. latifolia que cresce na borda das manchas em época de seca completa, com as glumelas ainda presas as raízes. 3c. Detalhe do ramo emergente do colmo. 3d. Espigueta, que encerra o fruto. 3e. Espiguetas.

das flores, a produção de frutos e sua maturação são eventos que ocorrem rapidamente nessa espécie, e necessitam, por parte da planta, de um investimento de energia concentrado em um espaço de tempo curto para posterior dispersão.

Tanto no Bracinho, quanto no Amolar, a emergência de botão e a abertura das primeiras flores foi ao final do mês de abril e início de maio, com eventos seguidos de produção e maturação de frutos (Figuras 8 e 9). Isso revela uma sincronia para as manchas de arroz que estão ao longo do rio Paraguai. A análise de regressão sobre o nível de água na mancha e sobre o comprimento do dia, tanto para o Amolar quanto para o Bracinho, sugere que a fenofase de emergência dos botões pode estar relacionada com ambos os fatores ambientais (Figuras 10-13).

Após a emergência dos botões, a planta leva de uma a duas semanas para a abertura das primeiras flores. Não foi observada a presença de visitantes florais no período de coleta e acredita-se que a sua polinização ocorra por anemofilia, assim como a da maioria das gramíneas. Para o Amolar, estimou-se que $60 \%$ das manchas tivessem a 
presença de botões no início do mês de maio, ao passo que nas manchas do Bracinho a estimativa para o início do mês maio foi de 55\% (Figuras 14 e 15).

A fase de floração se iniciou no fim de abril nas duas áreas, com média de $11 \%$, aumentando no início de maio, atingindo 60\% no Amolar e 50\% no Bracinho. Mesmo com a consequente produção de frutos e sua maturação, a formação de novos botões florais nas manchas foi observada, havendo um decréscimo durante o pico de frutificação, e um acréscimo após a dispersão das sementes, iniciando um novo ciclo, embora com porcentagens menores. Até o período de início de nova inundação, foi observada nas manchas a presença de panículas com alguns botões, chamados de temporões, em 5\% do total da mancha para as duas áreas de estudo. Rathcke \& Lancey (1985) reportam que a temperatura tem importância crucial em diferentes ciclos de vida e eventos de plantas, inclusive para a floração. Diekmann (1996) discute que além da temperatura, outras variáveis ambientais também têm sido identificadas como fatores de regulação da floração. De acordo com esses autores, o fotoperíodo tem sido apontado também como regulador para início de floração, principalmente para plantas de vida-curta.

De acordo com Sarmiento (1992) e Almeida (1995), existe uma relação entre a fenologia reprodutiva de gramíneas nos ambientes de savanas tropicais e a estabilização pluviométrica. Eles reportam que as gramíneas perenes, de modo geral, reproduzem-se durante o período chuvoso, mas a época exata do ciclo reprodutivo varia entre as espécies. Contudo, para O. latifolia, outras variáveis como o comprimento do dia e a temperatura também estão associadas.

Oelke \& Mueller (1969) evidenciaram, para a espécie cultivada $(O$ sativa $\mathrm{L}$.), que a altura da lâmina d'água utilizada na inundação pode comprometer o desenvolvimento das plantas de arroz e verificaram redução na produção de grãos em lâminas d'água mais espessas, acima de $8 \mathrm{~cm}$. Entretanto, Alves (1990) não observou diferença na produção de grãos

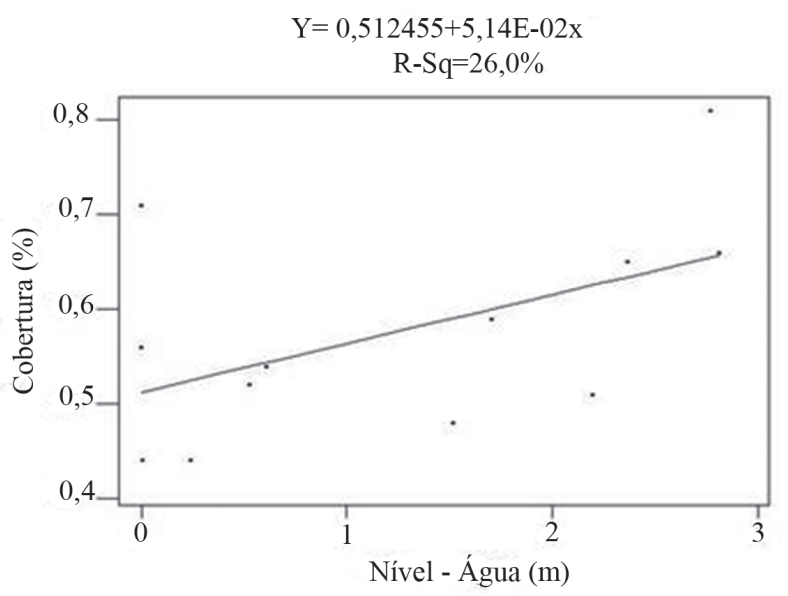

Figura 4. Análise de Regressão para porcentagem de cobertura em relação ao nível da água nas manchas do Amolar. $\left(\mathrm{r}^{2}=26,0 \% ; \mathrm{p}<0,001\right)$. em relação à altura da lâmina d'água de diferentes espessuras e cita a importância dela para o sucesso do ciclo reprodutivo. Furlani-Júnior (1995) sugere que a altura da lâmina d'água, para a espécie cultivada, está associada a outros fatores, tais como temperatura, radiação solar, cultivar utilizada e fertilidade do solo que, condicionando o ciclo reprodutivo, podem interagir, afetando ou não a produtividade de grãos.

Durante o período de reprodução, verificou-se a passagem de cinco frentes frias com vento sul, oscilando a temperatura entre dias quentes e frios (mínima $15^{\circ} \mathrm{C}$ e máxima $34,5^{\circ} \mathrm{C}$ ), sendo os períodos frios com duração de dois a três dias. Em um dos intervalos entre essas frentes frias, as manchas de arroz-do-campo apresentavam flores, o que, juntamente com a presença do vento sul com velocidades que oscilaram entre 1,4 e $12,5 \mathrm{~m} / \mathrm{s}$, pode ter favorecido a troca de pólen.

A temperatura é um parâmetro importante e geralmente é condicionante em grande parte do ciclo reprodutivo das espécies vegetais. Segundo Yoshida (1981) a temperatura ideal para o desenvolvimento da espécie cultivada situa-se entre $25^{\circ} \mathrm{C}$ e $30^{\circ} \mathrm{C}$, e temperaturas abaixo desse intervalo podem ocasionar estresse por frio. $\mathrm{O}$ autor ainda discute que temperaturas baixas, em especial menores que $20^{\circ} \mathrm{C}$ são um dos fatores abióticos que afetam o desenvolvimento, podendo interferir também no sucesso reprodutivo da espécie cultivada. Na microsporogênese, o frio $\left(t<20^{\circ} \mathrm{C}\right)$ ocasiona a esterilidade das espiguetas por meio da inviabilidade do pólen, enquanto que, no florescimento, o frio prejudica a deiscência das anteras e o crescimento do tubo polínico, resultando em baixa fecundação das espiguetas (Yoshida, 1981). Segundo Khan et al. (1986) para a espécie cultivada, a parte masculina das flores do arroz é mais sensível ao frio do que a parte feminina.

A duração do estresse é de extrema importância para a espécie cultivada. Experimentos de Yoshida (1981) mostraram que temperaturas de $12^{\circ} \mathrm{C}$ podem não provocar a esterilidade quando ocorrerem apenas dois dias de frio, entretanto

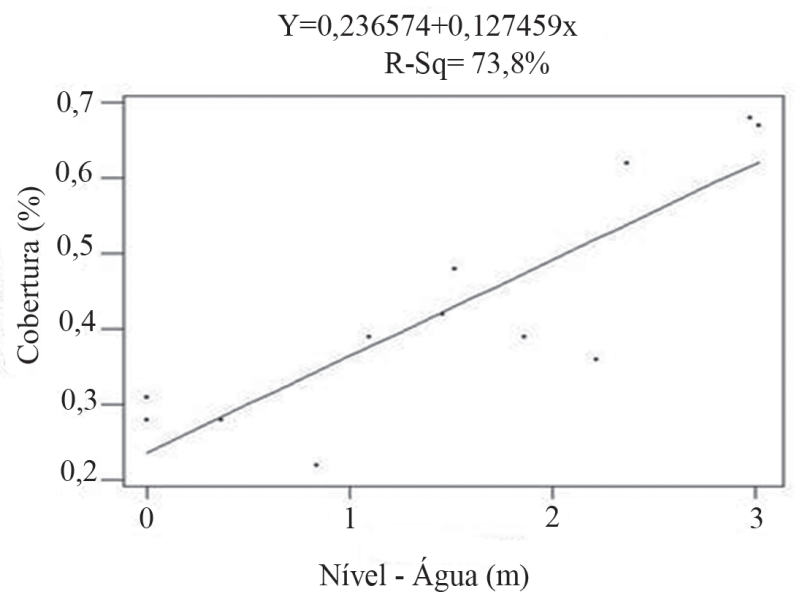

Figura 5. Análise de Regressão para porcentagem de cobertura em relação ao nível da água nas manchas do Bracinho. $\left(\mathrm{r}^{2}=73,8 \%\right.$; $\left.<<0,001\right)$. 


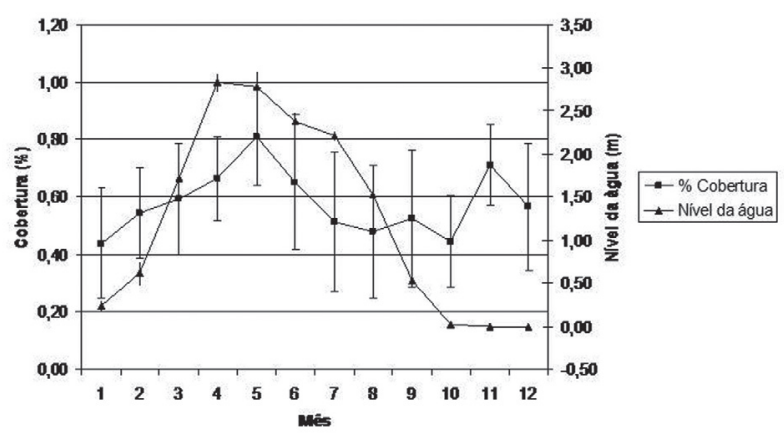

Figura 6. Porcentagem de cobertura em relação ao nível da água das manchas no Amolar ao longo de um ano (dez/2006-nov/2007).

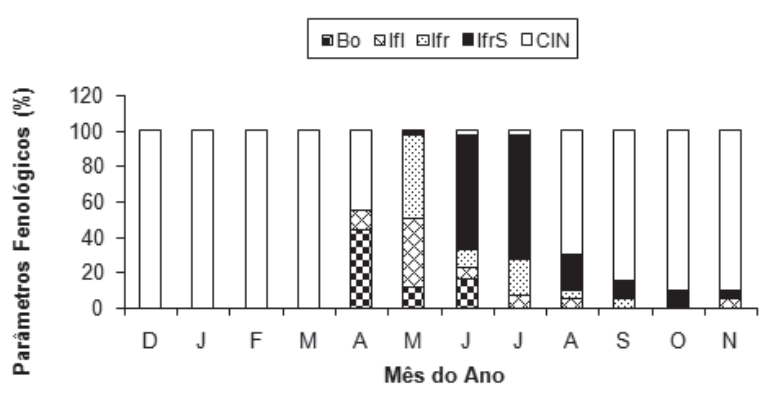

Figura 8. Eventos fenológicos ao longo do ano 2006-2007 para as manchas de O. latifolia na região da Serra do Amolar, Corumbá(MS), Brasil. (Bo-botão; Ifl-sinflorescência; Ifr-fruto maduro; IfrS-sinflorescência seca; ClN-colmos sem sinflorescência).



Figura 10. Análise de regressão para porcentagem de botões florais em relação ao nível da água nas manchas do Amolar. $\left(r^{2}=35,8 \%\right.$; $\left.p<0,001\right)$.

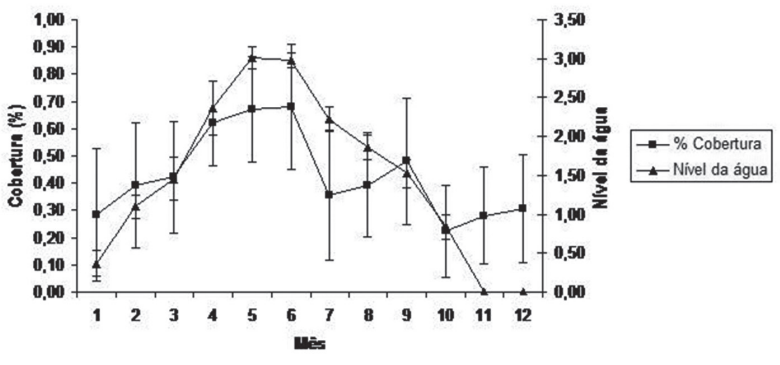

Figura 7. Porcentagem de cobertura em relação a nível da água das manchas no corixo Bracinho ao longo de um ano (dez/2006-nov/2007).

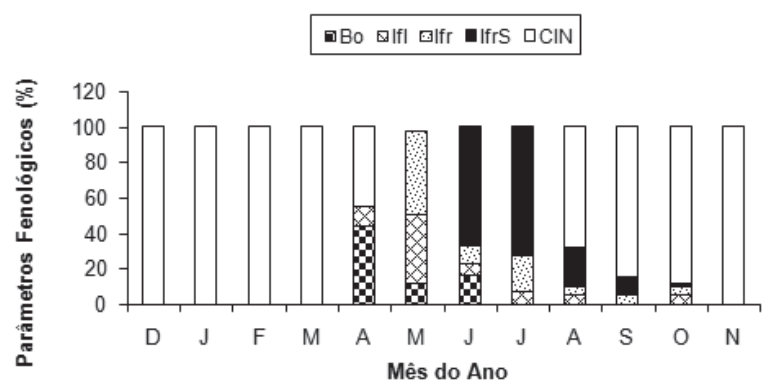

Figura 9. Eventos fenológicos ao longo do ano 2006-2007 para as manchas de O. latifolia no corixo Bracinho, próximos ao perímetro urbano de Corumbá (MS), Brasil. (Bo-botão; Ifl-sinflorescência; Ifr-fruto maduro; IfrS-sinflorescência seca; ClN-colmos sem sinflorescência).

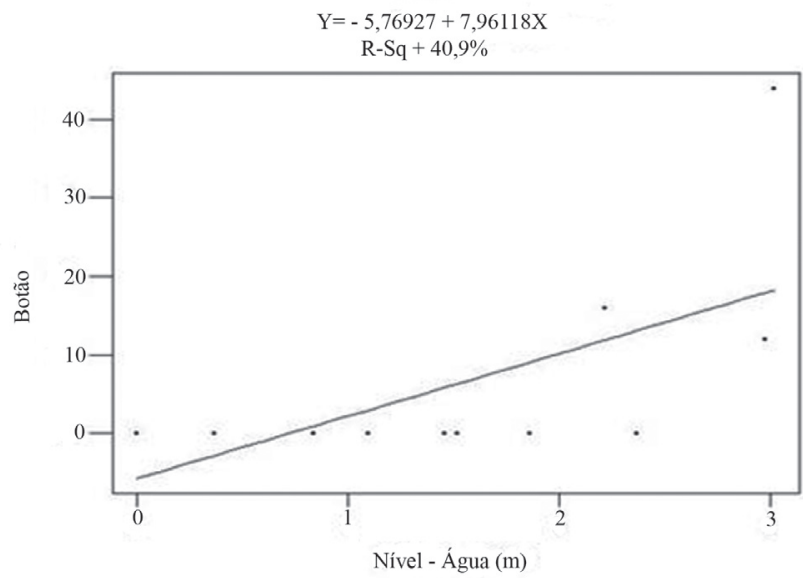

Figura 11. Análise de regressão para porcentagem de botões florais em relação ao nível da água nas manchas do Bracinho. $\left(\mathrm{r}^{2}=40,9 \% ; \mathrm{p}<0,001\right)$ 


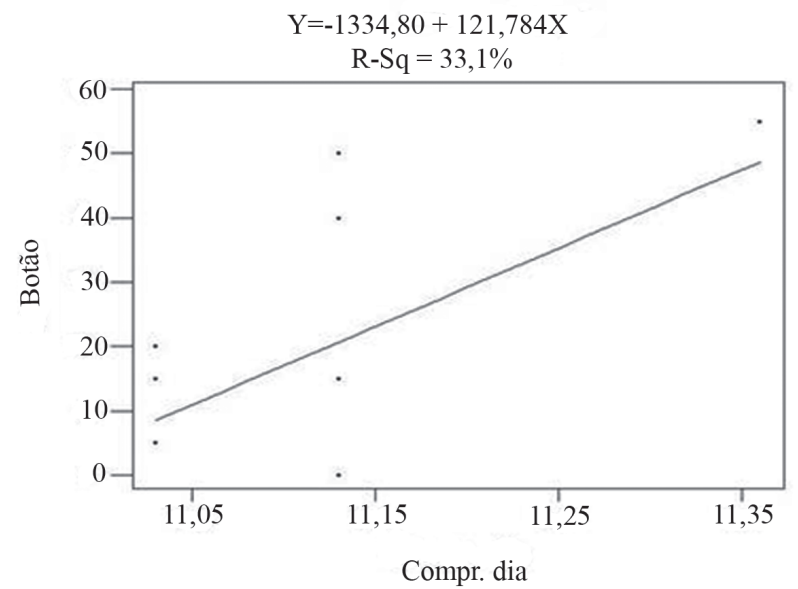

Figura 12. Análise de regressão para porcentagem de botões florais em relação ao comprimento do dia nas manchas do Amolar. $\left(r^{2}=33,1 \%\right.$; $\mathrm{p}<0,004)$.

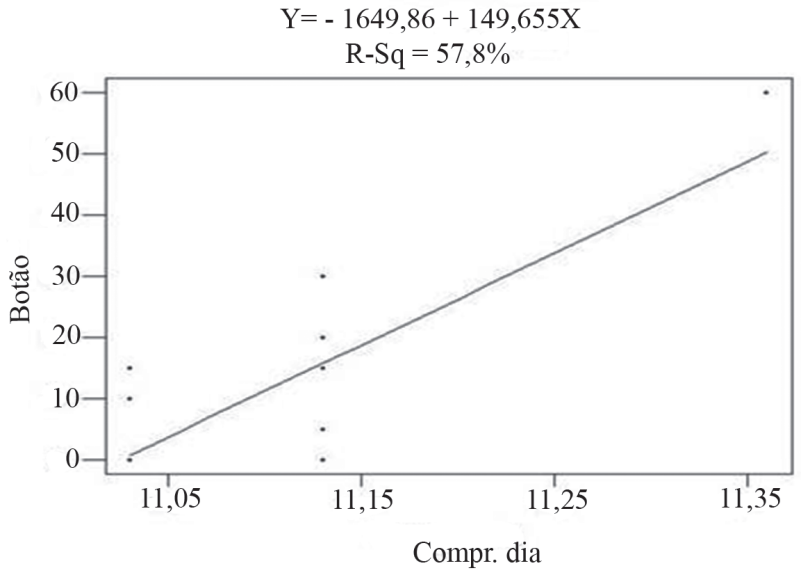

Figura 13. Análise de regressão para porcentagem de botões florais em relação ao comprimento do dia nas manchas do Bracinho. $\left(r^{2}=57,8 \%\right.$; $\mathrm{p}<0,003)$.

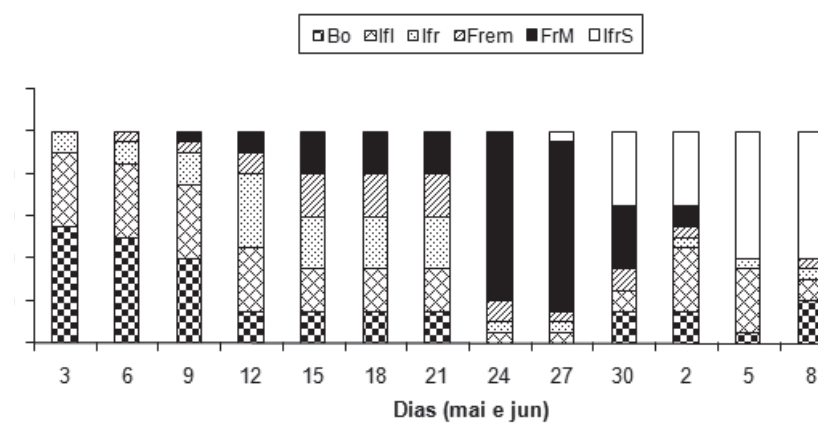

Figura 15. Eventos fenológicos a cada três dias para os meses de maio e junho de 2007 nas manchas de O. latifolia no corixo Bracinho, próximos ao perímetro urbano de Corumbá(MS), Brasil. (Bo-botão; Ifl -sinflorescência; Ifr- fruto jovem; Frem - fruto em maturação; FrM - fruto maduro; IfrS-sinflorescência seca).

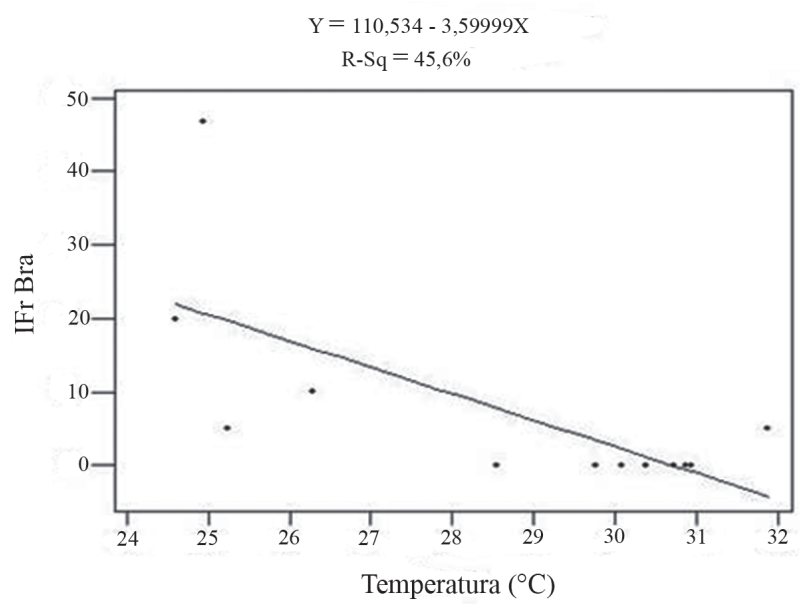

Figura 17. Análise de regressão para porcentagem de sinflorescências com frutos em relação à temperatura $\left({ }^{\circ} \mathrm{C}\right)$ nas manchas de arroz-do-campo do Bracinho. $\left(r^{2}=47,9 \%\right.$; $\left.<<0,001\right)$. 


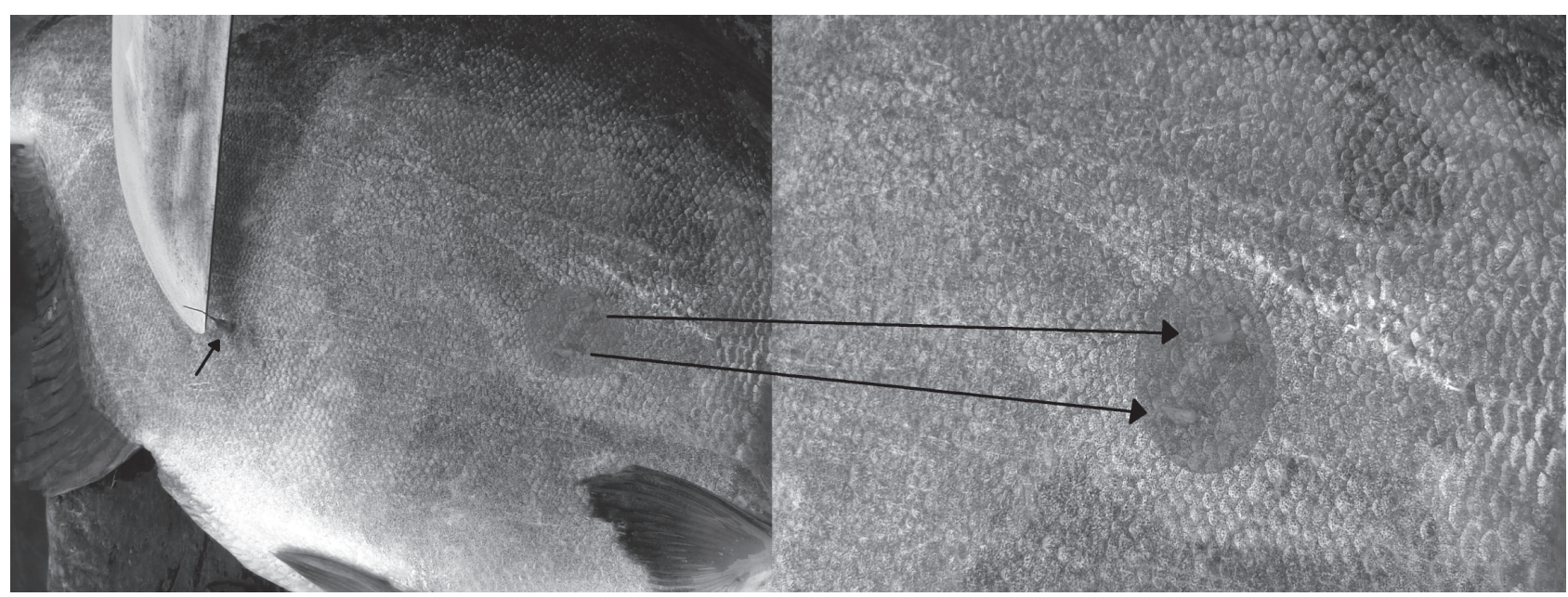

Figura 18. Fruto de O. latifolia preso às escamas do pacu (Piaractus mesopotamicus).

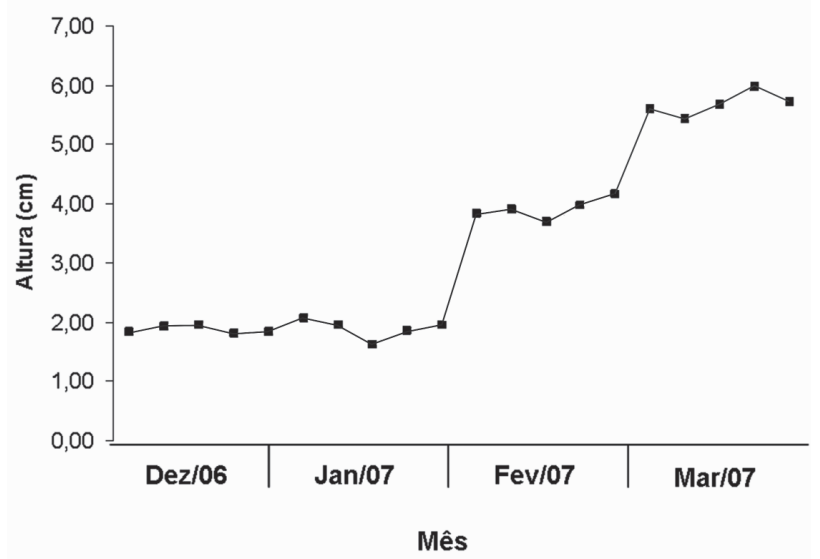

Figura 19. Crescimento de Oryza latifolia nas manchas de arroz do Amolar durante o período de dez/2006-mar-2007.

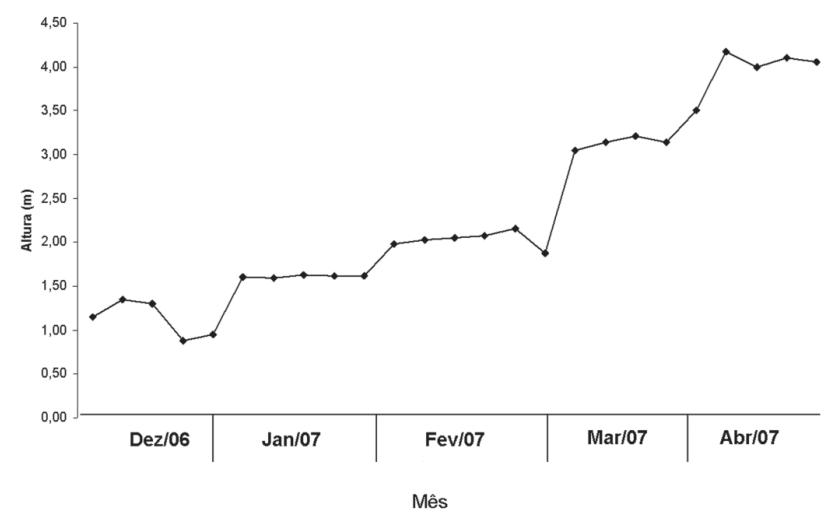

Figura 20. Crescimento de Oryza latifolia nas manchas de arroz do Bracinho durante o período de dez/2006-abr-2007.

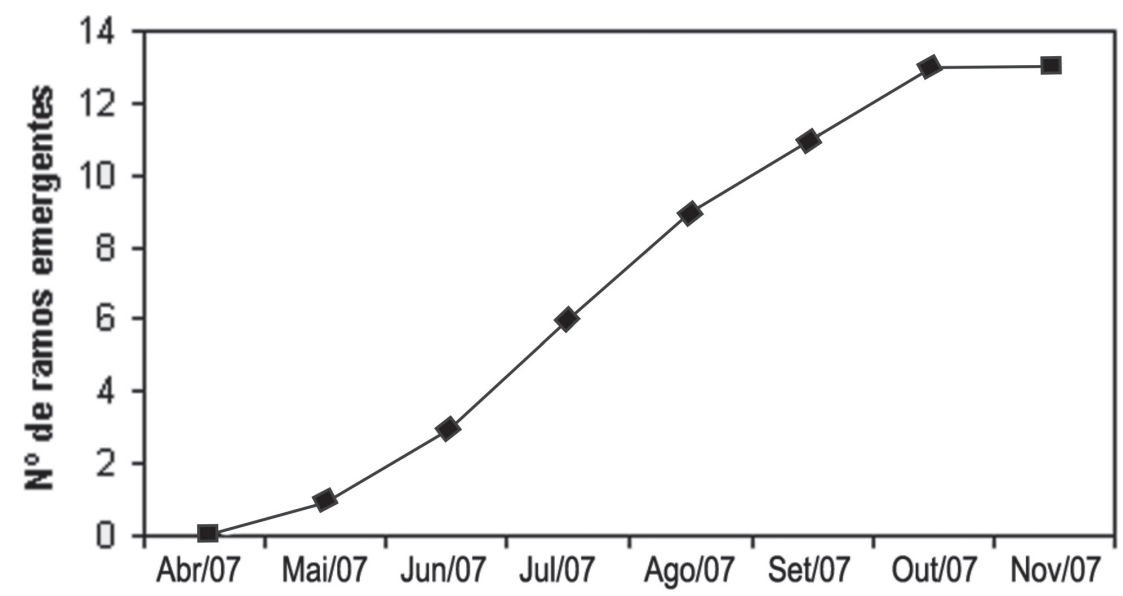

Figura 21. Média acumulativa de ramos emergente nos colmos de Oryza latifolia nas manchas de arroz durante o período de vazante (abr-2007 a nov-2007). 
podem induzir $100 \%$ de esterilidade quando a exposição ao frio for superior a seis dias. Nishiyama (1984) observou também que pode ocorrer esterilidade das espiguetas com temperaturas superiores a $20^{\circ} \mathrm{C}$ para as variedades no Japão. Sendo assim, a esterilidade das espiguetas é condicionada pela temperatura e sua duração. Neste trabalho, para a espécie nativa, não se verificou a esterilidade das espiguetas durante o ciclo reprodutivo, mesmo com as oscilações na temperatura. Contudo, após o período reprodutivo, em alguns indivíduos temporões, as espiguetas estavam sem fruto. Para garantir o sucesso reprodutivo com a produção de espiguetas férteis para a espécie cultivada, Cruz et al. (2006) controlaram a temperatura a fim de induzirem a exposição das panículas com espiguetas férteis a fim de selecionar genes resistentes ao frio. Os autores perceberam que a variação na temperatura interfere na microsporogênese e também na antese, e que esta ultima é mais sensível ao frio, inviabilizando a produção de frutos.

$\mathrm{Na}$ fase de frutificação, a maturação dos frutos esteve relacionada com o aumento da temperatura tanto para o Amolar $\left(\mathrm{r}^{2}-45,6 \%, \mathrm{p}<0,001\right)$ quanto para as manchas do Bracinho $\left(\mathrm{r}^{2}-47,9 \% ; \mathrm{p}<0,001\right)$. Dentre o período de permanência nas manchas do Amolar, observou-se que entre os dias 20 e 22 de maio, $80 \%$, em média, dos frutos classificados como "em maturação" alcançaram seu estágio máximo de maturação, i.e., pronto para dispersão, nas manchas estudadas. Esses dias apresentaram temperaturas médias de $27,5{ }^{\circ} \mathrm{C}$, sendo seguidos por dois dias de intensa frente fria com vento sul, queda brusca de temperatura $\left(16^{\circ}\right)$ e chuvas. Após esse período, $70 \%$ das sinflorescências maduras em cada mancha, apresentavam-se nuas, apenas $5 \%$ delas com frutos maduros persistentes nas sinflorescências. Ao mesmo tempo, $15 \%$ dos indivíduos já estavam com novos botões formados e $10 \%$ com as inflorescências abertas. O mesmo foi observado em Corumbá; entretanto, a porcentagem de permanência de frutos maduros nas sinflorescências ocorreu num período mais extenso, de 5 a 6 dias. Fato semelhante a esse ocorreu nas manchas de arroz-do-campo no ano de 2006. Antes da visita às manchas, no final de maio, uma frente fria com vento sul e chuvas passou pela cidade, derrubando os frutos maduros.

As análises de regressão mostraram que, para a fase sinflorescência seca, a temperatura e o vento estiveram relacionados, auxiliando também na dispersão, tanto no Bracinho $\left(\mathrm{r}^{2}=41,5 \%, \mathrm{p}<0,001 / \mathrm{r}^{2}=36,5 \%, \mathrm{p}<0,003\right)$ quanto no Amolar $\left(r^{2}=42,4 \%, p<0,001 / r^{2}=27,3 \%, p<0,008\right)$. O nível da água não apresentou relação significativa com a fase de frutificação, o que corrobora dados de FurlaniJúnior et al. (1995), nos quais o nível de água não esteve relacionado com o período de frutificação para a espécie cultivada (O. sativa).

Na maturação, os frutos de O. latifolia apresentam uma coloração preta, sendo esse o estágio pronto para ser disperso. Os campos de arroz, quando estão com seus frutos maduros, vistos a longas distâncias, podem ser reconhecidos pela coloração acastanhada.
O clima sazonal dessa região favorece a estratégia de dispersão de $O$. latifolia. A dispersão primária, para essa espécie, é por barocoria e a secundária, por hidrocoria, ocorrendo também zoocoria, como observado no pacu (Piaractus mesopotamicus) da Figura 18, com o fruto do arroz-do-campo preso às escamas.

\section{Considerações Finais}

Para a espécie O. latifolia, a dominância em relação a manchas de arroz pode ser explicada pelo seu modo de propagação, pelo qual os ramos na época da vazante acamam-se sobre a mancha, ocupando uma área maior e proporcionando a rebrota dos colmos, e também pela chegada das chuvas, que permite que novos indivíduos germinem na borda das manchas.

As variações nos caracteres fenológicos analisados sugerem que variáveis ambientais, como o nível da água e o comprimento do dia, condicionam a formação das sinflorescências e indicam que as fenofases do ciclo reprodutivo ocorrem em um intervalo de tempo relativamente curto. Estudos mais aprofundados, entretanto, são necessários para explicar os dois ciclos anuais de florescimento observados e para determinar o papel relativo de cada fator ambiental no controle do florescimento. O. latifolia é uma espécie dominante nessa paisagem, tolerante à inundação, importante economicamente por seu alto valor forrageiro e como fonte de germoplasma nativo para o melhoramento do arroz . A espécie tem potencial de utilização pela comunidade local, que pode agregar valores ao seu produto.

Abordagens que enfoquem o estudo fenológico e a descrição de gramíneas nativas, em especial no Pantanal, começam a preencher uma importante lacuna. A continuidade de estudos como esse por um período de tempo mais extenso, será de grande importância científica e agregará valor ao conhecimento sobre as espécies de gramíneas nativas desse bioma.

\section{Agradecimentos}

À CAPES pela concessão da bolsa; ao CNPq pelo financiamento; ao Programa de Pós-Graduação em Biologia Vegetal (UFMS) e Ecoa pelo apoio logístico . A Leila Costa Name pelas ilustrações e ao Lennon Godoi pelo auxílio com a parte gráfica. A Comunidade do Amolar, em especial a Waldemar e Iracy Magalhães e família pela amizade e contribuições essenciais.

\section{Referências Bibliográficas}

Allem, A.C. \& Valls, J.F.M. 1987. Recursos forrageiros nativos do Pantanal Matogrossense. Brasília, EMBRAPA/CENARGEN.

Almeida, S.P. 1995. Grupos fenológicos de gramíneas perenes de um campo cerrado no Distrito Federal, Brasil. Pesquisa Agropecuária Brasileira. 30: 1067-1073 
Alves, M.C. Efeitos do manejo de água na cultura do arroz (Oryza sativa L.) irrigado por inundação. Botucatu, 1990. Dissertação (Mestrado em Agronomia) - Faculdade de Ciências Agronômicas/UNESP, 1990.

Ana; GEF; PNUMA; OEA. 2004. Implementação prática de Gerenciamento Integrado de bacia hidrográfica para o Pantanal e Bacia do Alto Paraguai: Relatório Final. Brasília, TDA Desenho e Arte.

Barbosa, M.M. 2007. Desenvolvimento e aproveitamento de alimentos de origem vegetal por três comunidades do Pantanal e Cerrado. (Relatório técnico CNPQ).

Bortolotto, I.M. \& Guarim Neto, G. 1998. Etnobotânica e Conservação da Natureza em uma Escola Rural do Distrito de Albuquerque Corumbá - MS: Uma abordagem para a Educação. Cuiabá, Revista de Educação Pública 7:11.

Cruz, R.P.; Milach, S.C.K. \& Federizzi, L.C. 2006. Rice cold tolerance at the re trazproductive stage in a controlled environment. Scientia Agricola 63(3): 255-261

Diekmann, M. 1996. Relationship between flowering phenology of perennial herbs and meteorological data in deciduous forest of Sweden. Canada, Canadian Journal of Botany 74: 528-537.

Furlani-Júnior, E.; Machado, J.R. \& Velini, E.D. 1995. Épocas de início da inundação do solo e altura da lâmina de água em arroz irrigado. Campinas, Bragantia 54(2): 413-418.

Hamilton, S.K.; Sippel, S.J. \& Melack, J.M. 1996. Inundation patterns in the Pantanal wetland of South America determined from passive microwave remote sensing. Archiv für Hydrobiologie 137(1): 1-23.

Hesla, B.I.; Tieszen, H.L. \& Bouton, T.W. 1985. Seasonal water relation of savanna shrubs and grasses in Kenya, East Africa. Journal of Arid Environment 8:15-31

Irgang, B.E.; Pedralli, G. \& Waechter, J.I. 1984. Macrófitos Aquáticos da Estação Ecológica do Taim, Rio Grande do Sul, Brasil. Roessleria 6: 395-404.

IRRI - International Rice Research Institute. Rice Knowledge Bank. Disponível em: www.knowledgebank.irri.org/wildricetaxonomy.

Khan, D.R.; Mackill, D.J. \& Vergara, B.S. 1986. Selection for tolerance to low temperature-induced spikelet sterility at anthesis in rice. Crop Science, Madison, 26(4): 694-698

Khush, G.S. 1997. Origin, dispersal, cultivation and variation of rice. Plant Molecular Biology, The Netherlands, 35: 25-34.

Matos, R.J.C. 1875. Viagem de Porto Feliz a Cidade de Cuyaba: 22 de junho de 1826. Rio de Janeiro: Revista Trimestral do Instituto Histórico Geographico e Ethnographico do Brasil 38: 367-441.

Metraux, J.P. \& Kende, H. 1984. The celular basis of the elongation response in submerged deep-water rice. Planta, Berlin, 160(1): 73-78.

Nishiyama, I. 1984. Climatic influence on pollen formation and fertilization. Pp. 153-171. In: Tsunoda, S.; Takahashi, N. (Ed.). Biology of rice. Tokyo, Japan Scientific Societies Press.
Oelke, E.A. \& Mueller, K.E. 1969. Influence of water management and fertility on rice growth and yield. Agronomy Journal, Madison, 61: $227-230$.

Oliveira, G.C.X. 1991.Variabilidade ecológica e genética em espécies brasileiras de Oryza. In: Anais do Encontro Sobre Temas de Genética e Melhoramento 8: 15-16. Piracicaba.

Oliveira, J.E. 2002. Da pré-história à história indígena: (Re) Pensando a arqueologia e os povos canoeiros do Pantanal. Tese (Doutorado em História-Arqueologia). Porto Alegre, PUC/RS.

Pott, V.J. \& Pott, A. 2000. Plantas Aquáticas do Pantanal. Brasília, Embrapa Centro de Pesquisa Agropecuária do Pantanal.

Prance, G.T. \& Schaller, G.B. 1982. Preliminary study of some vegetation types of the Pantanal, Mato Grosso, Brazil. Brittonia 34(2): 228-251.

RadamBrasil. Folha SE. 21 Corumbá and SE 20. Levantamento de Recursos Naturais, 27. Rio de Janeiro.

Rathcke, B. \& Lacey, E.P. 1985. Phenological patterns of terrestrial plants. Annual Review of Ecology and Systematics 16: 179-214.

Reitz, R. 1982. Flora ilustrada Catarinense: Gramíneas. Pp. 576-581.

Rosa, M.S.; Dos Santos, P.P.; Veasey, E.A. 2006. Caracterização agromorfológica interpopulacional em Oryza glumaepatula. Bragantia 65(1): 1-10. Campinas

Rubim, M.A.L. 1994. A case study on life-history of wild rice - From germination to emergence of inflorescence. In: Morishima, H. \& Martins, P.S. (Ed) "Investigations of plant genetic resources in the Amazon Basin with emphasis on the genus Oryza . Report of 1992/1993 Amazon Project.

Sarmiento, G. 1992. Adaptative strategies of perennial grasses in South American savannas. Journal of Vegetation Science 3: 325-326.

Silva, D.A. \& Klink, C.A. 2001. Dinâmica e foliação e perfilhamento de duas gramíneas C4 e uma C3 nativas do Cerrado. São Paulo, Revista Brasileira de Botânica 24(4): 441-446.

Silva, J.S.V.; Adbon, M.M. 1998. Delimitação do Pantanal Brasileiro e suas Sub-Regiões. In: Pesquisa Agropecuária Brasileira. Brasília. Número especial 33: 1703-1711.

Soriano, B.M.A. 1997. Caracterização climática de Corumbá, MS. Boletim de Pesquisa, 11. Corumbá, Embrapa-CPAP.

Souza, V.C. \& Lorenzi, H. 2005. Botânica Sistemática: Guia Ilustrado para identificação das famílias de Angiospermas da flora brasileira, baseado em APG II. São Paulo, Instituto Plantarum. Nova Odessa.

Veasey, E.A.; Silva, E.F.; Schammass, E.A.; Oliveira, G.C.X. \& Ando, A. 2008. Morphoagronomic genetic diversity in American wild rice species.Curitiba: Brazilian Archives of Biology and Technology 51(1): 95-104.

Yoshida, S. 1981. Fundamentals of rice crop science. Los Baños: International Rice Research Institute. Pp. 1-63. 